\title{
Notes on Operations
}

\section{Rethinking and Transforming Acquisitions: The Acquisitions Librarian's Perspective}

\section{Carol Pitts Diedrichs}

\begin{abstract}
The skills used by acquisitions and serials experts in the past will be needed in the virtual library of the future. However, the context, environment, scope of duties, and use of those skills has changed. The managerial, business, and personal skills that will be needed for acquisitions librarians to remain central to the virtual library are discussed. I will also consider the issues of self-leadership, management, and survival in a continual state of change, and the need for creativity and innovation, as well as more traditional skills such as purchasing expertise, negotiation skills, and contract administration.
\end{abstract}

\begin{abstract}
A
As part of evaluating current acquisitions tasks and skills, I reviewed the job description for the head of the Acquisition Department at the Ohio State University (OSU) Libraries as it existed in 1987. Ten years ago, the head of the Acquisition Department was required to:
\end{abstract}

1. administer the operation of the department with responsibility for the full range of activities associated with ordering, receiving, and accounting for all materials (monographs and serials, print and nonprint);

2 , formulate policies and oversee the development and implementation of operational procedures in consultation with department personnel;

3. supervise directly two faculty members and three senior paraprofessional staff, and indirectly, a staff of more than 50 CCS (Classified Civil Service) and students;
4. serve as a member of the libraries' Administrative Staff Conference;

5 . work closely with the head of the Cataloging Department, the preservation officer, the collection development officer, and public services personnel; and

6. represent the libraries in relevant national forums, and maintain communication with booksellers and vendors for library materials.

The qualifications that appeared in the position description that was advertised included:

- A master's degree in library science from an ALA-accredited program

- Substantial relevant experience in the acquisitions operation of a large academic or research library

- Demonstrated ability to lead and to direct professional and support staff

Carol PitTs Diedrichs (diedrichs.1@osu.edu) is Interim Assistant Director for Technical Services and Head, Acquisition Department at the Ohio State University Libraries, Columbus. Manuscript received August 25, 1997; accepted for publication December 16, 1997. 
in a large and complex technical services operation

- Ability to foster a collaborative approach to problem solving

- Ability to analyze work processes, especially to plan for applications of technology

- Ability to communicate clearly and effectively both orally and in writing

In general, the underlying skills required in 1987-managing, collaborating, and administering-are still required today and have not changed much. What has changed are the context, environment, scope of duties, and use of those skills for the benefit of the libraries. The changing nature of libraries will require librarians with core skills such as collaboration, flexibility, and adaptability. The virtual library might change the organizational structure in such a way that no identifiable acquisitions department will continue to exist, but the core skills that successful acquisitions librarians possess will still be required for the acquisition of library materials.

\section{Acquisitions Tasks Today}

Magrill and Corbin (1989) identified 10 functions of acquisitions: obtaining information about materials; initiating the purchasing process; maintaining records for materials ordered; receiving and checking materials; authorizing payment for materials; clearing order records; claiming and canceling orders; handling materials that need special treatment; dealing with special situations; and developing and analyzing performance statistics. In the later chapters, they also revealed the specific aspects of these functions such as bibliographic searching, vendor-controlled order plans, gifts and exchanges, and acquisition of serials. These tasks certainly reflect many of the acquisitions librarian's daily activities, but new tasks are present as well, such as acquisition of electronic products (including licensing), management of new outsourcing activities (such as PromptCat or shelf- ready approval plans), or copy cataloging performed at point of receipt.

It is easy to believe that the times in which one lives are times of extraordinary change. But in looking back only 30 years or so, it is clear that significant changes have occurred with a decided impact on the acquisitions functions of today. Reid (1995) provided a taste of the changes that have occurred in acquisitions tasks since the 1960s. For example, acquisitions in 1969 involved working with manual systems; using the National Union Catalog, Books in Print, Publishers Weekly, Forthcoming Books, Book Publishing Record, Cumulative Book Index, and publishers' catalogs to verify orders; checking the card catalog to be sure that a title was not already owned and seeing whether the library owned related editions; and checking paper order files to see whether a title was on order or in process. Orders were sent by U.S. mail; rush orders went by airmail. Communication with vendors took place via mail; there were no 800 phone numbers, no library-generated credit memos, and few form letters. Repetitive data entry was standard-creating the order request, creating the purchase order, etc. It could take a serials invoice person up to three months to review a large serials invoice before it could be approved for payment. If vendors had any automation, it was crude and unsophisticated.

The intervening years have seen the development of the OCLC Online Computer Library Center, Inc. utility as a verification tool, the availability of 800 phone numbers and ISBNs, the advent of the personal computer (PC) and PCbased products such as BIP Plus, automated acquisitions systems in libraries and interfaces with automation in the vendor's shop, use of the MachineReadable Cataloging (MARC) record format in vendor databases, electronic ordering, and access to vendors through the Internet (Reid 1995).

As an outgrowth of the set of tasks assigned to acquisitions librarians, these librarians have developed a set of skills that are essential for success in managing acquisitions today as well as in the 
future. In reviewing this history of the acquisitions profession, Reid closed her presentation by identifying acquisitions librarians as being $(1995,270-71)$ :

1. "No longer immersed in the nittygritty details of reviewing each order and assigning vendors"

2. "Technologically adept"

3. Part of a larger decision-making process than in the past-decisions cannot be made in isolation

4. "Generalists [who must] have more of an overview of selection and of acquisitions by many means, including interlibrary loan, electronic document delivery and online databases, cataloging, and end processing"

5. "Able to grasp not only the details, but also the overview. They must make their needs known. They must be able to analyze a problem, come up with alternatives, select and implement one, scrap it if it doesn't work, and then adopt another solution. Acquisitions librarians must be decision-makers"

6. Business people

7. People who are "[b]uying not only books, journals, microforms, and tapes, but CDs, CD-ROMs and videos, and database access, as well. More and more we are buying information customized for the user's immediate need: we are negotiating CD-ROM and online database contracts and we are assigning IDs and passwords to our users."

It is easy to list the current tasks involved in the management of acquisitions processes today and difficult to know for sure what those tasks will be in the future. Thus, acquisitions librarians must focus on the skills that will be needed in the future rather than on the tasks. Nisonger (1994) provides a clear reminder that students entering library school programs today will not finish their careers until 30 or 40 years from now. He argues that those students must be prepared for the fundamentals of librarianship today as well as be prepared to manage unforeseen and unimaginable change. His arguments can be extended to those already practicing in the field.

I conducted an extensive review of the management literature looking for the current thinking on leadership and management skills that would be applicable to the acquisitions professional in the future. Much of the current management theory first appears in the journal literature but is then synthesized effectively in subsequent monographic literature. This paper reflects the thinking of leading management theorists and practitioners whose works have been published in the last five years. This period was selected because the field of management theory has undergone considerable reorientation during this time. As they apply to acquisitions librarians, these skills fall into three general categories: managerial, business, and personal.

\section{Managerial SkILls}

Acquisitions librarians are first and foremost managers. In my assessment of the management and library science literature, five managerial skills emerged as the most crucial: having a vision and setting goals, creativity and innovation, leadership, problem management, and change management.

\section{HaVing a Vision and Setting Goals}

Vaill $(1993,13)$ defines a vision as:

an expression that does not merely describe why an organization exists and what products and services it intends to deliver A vision is a portrayal of an organization's intended activities and character in vivid terms that capture an organization's human meaning and value. A vision is full of possibility A vision is a motivational statement as much as it is a descriptive statement. It expresses the feeling that those who hold it have for the organization and its work. The bare statement of why the organization exists and of what it intends to do we will call the 'mission.' Its human meaning and the difference that the mission makes in the 
world we will call the 'vision.' If the mission is the words, the vision is the music.

The purpose of a vision is to excite and inspire those who work for the department as well as state the fundamental values that will permeate every decision, policy, or action of the department (Phillips 1993). For example, a vision that could be written for OSU's Acquisition Department might read as follows: to provide the best acquisition, receipt, invoicing, cataloging, project control, and management services so that the department can help the collection managers deliver high quality service to the university's patrons. A vision for a particular goal can help show what things might be like once the goal is accomplished.

Visions are long-range initiatives. They should be reasonable enough that there is a good chance of achieving them. However, they should also be just enough out of reach that an extraordinary effort will be required to achieve the vision. Particularly for middle managers such as acquisitions librarians, visions should be within the control of the manager to achieve. Visions that require changes beyond the manager's reasonable control are not realistic. For example, a vision that requires the addition of 10 new positions during a hiring freeze is neither reasonable nor within the control of the manager. Visions should also be well known by everyone who is a part of making the vision happen. Finally, a fundamental component of any vision is that it inspire everyone with the prospect of making that vision a reality (Yeomans 1985). Visions need to exist at all levels of an organization. Acquisitions librarians must set accomplishable visions for their departments and attempt to influence the visions being set for technical services and the library as a whole.

In 1996, the Copy Cataloging Section at OSU was merged with the Acquisition Department. Following that merger, librarians in the department envisioned that excellent service could be provided if an eight-week copy cataloging backlog were eliminated and a one-week tumaround were maintained on that material in the future. The staff believed that if they eliminated the copy cataloging back$\log$, there would not be as much opportunity to misplace unprocessed books. The department would either be able to locate rush material more quickly or have already processed the title by the time the rush request was received. The department would not receive as many complaints or be considered inefficient. Instead, the department would be considered a place where a collection manager could get real help and assistance. The department would improve and enhance its reputation for providing excellent service.

\section{Fostering CREativitT AND \\ INNOVATION}

"Creativity is the ability to free yourself from imaginary boundaries, to see new relationships and patterns and in that way accomplish new things of value. . " (Yeomans 1985, 53). When new trends are emerging, people who can think creatively are especially valuable. They are the people who first ask such questions as: Do approval titles really have to be reviewed by collection managers? Creative thinkers often rely on intuition to free their thinking process. Intuition has been defined as the ability to see the woods, not just the trees, to see the big picture, or to grasp opportunities. This combination of creativity and intuition allows one to think unencumbered by the way things have always been. Intuitive thinking is an important skill to have or acquire in the current library environment because of a number of factors that reflect our current world: a high level of uncertainty, few precedents on which to base decisions, few reliable facts available to guide decisions, a limited time period in which decisions often must be made, and often the availabiltiy of several plausible options to consider (Phillips 1993).

Many people see creativity as being the province of someone else, particularly artists and other "creative types"; everyone else just plods along. Yeomans (1985) has identified four common barriers to creative thinking. The first is making wrong assumptions. Usually individuals 
think that because things have been a certain way, they must stay that way. "That shuts off a whole range of new possibilities before they are even considered and assures that any ideas you come up with are nothing more than fine tuning of what you have done before.... Wrong assumptions set up imaginary boundaries and restrictions that suppress innovative thinking" (p. 54).

The second barrier is going for a fast solution. Haste can lead to overlooking alternative solutions or ideas that will lead to solutions. The third barrier is not wanting to make mistakes. Any creative or original idea means going outside the known world to the unknown. In order to explore these unknown areas, librarians must be prepared to make mistakes, regroup, and begin again. The final barrier is using only the left brain. The left brain is cautious, orderly, analytical, and logical. It is the part of the brain that keeps one on time, helps one count, and allows one to do procedural work. The right brain is the maverick, "let's try it" side. That part of the brain is responsible for creative, emotional, sensitive, fun-loving, and risktaking behavior. Today's culture encourages and rewards left brain thinking.

Most librarians have had experience with very creative thinkers who always have new ideas and, in some cases, seem willing to implement these ideas, often just because they seem interesting. Creativity is only the first step in the process of innovation. Creativity deals with idea generation in general, while innovation deals not only with idea generation but also with the implementation of those ideas (Olaisen, Lovhoiden, and Djupvik 1995). This is one of the valuable skills that successful acquisitions librarians will bring to the change process: the ability to implement new ways of doing business. Acquisitions librarians have to create their own future as librarians; being an acquisitions librarian is secondary to the more general role as a professional librarian. Achieving successful innovation means more than just encouraging the innovators, however. It is also important to have a system that supports ideas from the con- ceptual stage right through to production. Libraries need both creativity and innovation; they need staff to think beyond the box but also with a realistic view of how something can be implemented.

\section{LEADERSHIP}

Obviously, managers will continue to deal with personnel issues on a daily basis. The aspect of managing personnel that is of most concern is not the nitty-gritty but rather the issue of leadership. One particular aspect of leadership—developing a sense of responsibility in staff-is fundamental to the success of acquisitions librarians. In order to develop (or enhance) a sense of responsibility in staff, leaders must give staff full responsibility to do their own work and must develop mutual confidence and respect. In turn, this will reduce the need for supervision to a minimum. Leaders must allow freedom of expression, which can allow staff to become more self-directed under the guidance and direction of policies and workflows established by the organization. Managers must focus on being sure they get the results they need and that no reasonable library policy is violated rather than directing every detail of how the work is accomplished (Van Fleet 1973).

One technique for allowing this freedom of expression is to use mission-type orders. Mission-type orders focus on telling the employee what needs to be accomplished, not how it has to be done. The manager needs to convey the mission to be accomplished or problem to be solved, the limitations imposed, and the resources available. Both responsibility and authority must be given; they go hand in hand.

Mission-type orders are also a good way for acquisitions managers to encourage proactive behavior. Proactive managers identify a problem, concern, or service enhancement before a crisis develops. In contrast, reactive managers tend to restrict their actions to problems brought to them. Crises in the organization dictate their actions. The proactive manager identifies a problem-such as a four-week delay in the review and processing of approval material. That problem and the desired outcome-a reduction in the time needed to 
process the material to one, two, or three weeks - is presented to staff. The orderto identify ways to reduce the processing time to one, two, or three weeks-is given to the staff to solve. This is a far more effective strategy than simply identifying a potential solution without the input of the staff most directly involved.

Using this approach also requires managers to back the decisions made by their employees. Managers must let employees put their methods to work. Staff members will not stick their necks out when thev are afraid of having their heads chopped off. Accountability is equally important; it is fair to hold staff accountable for results. Of course, this does not mean berating them when something goes wrong, but rather evaluating the issue to determine what can be done differently next time.

An important part of developing this sense of responsibility is keeping staff informed. Thompson $(1994,120)$ states that:

Employees frequently feel left out of the loop, and in our CNN [Cable News Network] society, knowledge and information wield tremendous power. It isn't necessarily that those in positions of power and authority withhold information as much as they fail to keep people informed. ... The reluctance to tell everyone that there is in fact no news gets misconstrued as an attempt to keep people in the dark. In other cases, the hesitancy of leaders to admit their mistakes is seen as another such concealment strategy. ... The failure to admit our shortcomings in the view of those who already are aware of them can nearly disqualify us from being seen as a leader.

The capabilities of integrated library systems today require staff to use independent thinking to be successful. These systems function best when staff are empowered to make skilled decisions throughout the workflow. The need to empower staff is a matter of survival.

\section{Problem Management}

The fourth managerial skill is problem management. It is not possible here to discuss specific techniques involved in problem management. Instead, the focus here is on the process of problem management itself. The first step in many problem-solving models-problem definition-often assumes that the manager already knows what the problem is. Lubans (1994, 140) uses the term "mess finding" as the "the fuzzy, ineffable, first intimation that something is going or has gone awry and that missing or ignoring this initial step might explain why our best efforts sometimes fail." In the problemdefinition stage, managers can also look for ways to improve a process even where there isn't a problem, but where there are different ways to achieve results.

The problem-definition stage is very important because, as with an illness, the symptoms often mask the problem. The apparent problem might not be the real issue that needs to be resolved. Managers often treat the symptoms-the most obvious thing that is not functioning correctlyrather than determine the fundamental problem and address that. Of course, it feels good to do something with positive and immediate effects. However, that resolution will be short-lived if the root of the problem has not been addressed. In most cases, the root problem will simmer and smolder and manifest itself again, at which point more energy will have to be directed toward its resolution.

For the most part, managers find themselves surrounded by problems. As a result, the key issue is to determine which ones deserve attention. Thus, the essential first step is to get a clear, objective picture of the problem, who is involved, and who is affected. The manager must also determine what is not the problem and understand the limits of what can be achieved.

For example, until recently, the Acquisition Department at OSU did not have enough personal computers for each staff member to have dedicated access to departmental resources. Much time was spent juggling work and access time to appropriate equipment. Obviously, there was a solution-buy more computersbut the library had other priorities at the time for its equipment budget. In defining the problem and the limitations, it was 
clear that the library was not going to be able to replace all PCs immediately. It was also clear that the dumb terminals were actually useful for some activities and specifically needed for activities such as serials check-in, where we already had two printers. Thus, the primary question became, If the department received new $\mathrm{PCs}$, where would they be most effectively deployed?

The second step-putting a problem in context - can be facilitated by various techniques. For example, "reframing" is a technique that allows you to put yourself in someone else's shoes and consider the problem from their perspective. Another technique-force-field analysis-asks you to describe the worst-case scenario as well as the ideal situation. The situation regarding equipment was right in the middle between these two extremes.

The next stage of the analysis focuses on the forces that are making the situation better or worse. As a result, the forces affecting the problem can be identified (Phillips 1993). The third techniquebrainstorming-is the one most often misused by managers. The real idea behind brainstorming is to produce as many ideas a possible without evaluating them. Brainstorming is also a technique that an individual can use for problem solving, not just a group. Finally, Muir $(1995,103)$ defines benchmarking as a process that "compares a library's work processes to those of other libraries. The goal of this exercise is to identify other libraries with better procedures and to adopt their 'best practices,' thereby improving library operations."

These techniques are useful because they facilitate thinking about problems in new ways. For any given problem, there are likely to be several alternatives for solving the problem or managing the solution, the third step in the process. The term "problem management" rather than "problem solving" has been used here because problem management is not just about finding a solution. Sometimes there is no solution to a problem. In our example, rather than spending extraordinary time debating the solution, the Acquisi- tion Department had to focus on managing the situation and coming to terms with how to schedule and share the existing resources effectively. In such circumstances, one of the main objectives of problem management is helping people come to terms with the situation.

This part of managerial skills should not be limited strictly to the evaluation of problems. These techniques and ways of looking at problems are also useful for looking at new ways of doing business. One of the key things acquisitions librarians must learn to do is ask questions about their work. Finding time to think about what we are doing rather than simply reacting is difficult. But, taking time to ask questions and examine assumptions can result in new ideas and approaches. For example, Yeomans (1985) identifies two excellent questions to ask: Is this function or project really contributing something, or could it be disbanded? What would be the effect on the organization if it weren't around? During one hiring freeze at OSU, this question was posed about the extensive searching done on serial check-in duplicates before disposal. As a result, the process was changed from extensive searching to holding the duplicates on shelves for four months before disposal. The re-searching done before disposal was eliminated. The assumption was made that any major problems with the duplicate, such as an invoice for payment, would reveal themselves within the four months. At the end of four months, rather than discarding the pieces as had been done previously, the duplicates were sent to the appropriate destination library. The pieces could be used as fillins or staff at the location might know of reasons for retaining the duplicates. This new approach works well for everyone and eliminated a labor-intensive searching process.

\section{Change Management}

Change management is an extensive topic with many aspects. This section will focus on a few key thoughts on this topic. Most are about the realities of today and the mandate librarians have to keep them- 
selves poised and ready to deal with a world in constant change. First, according to St. Lifer (1996, 26),

better than six out of ten library staff say their job responsibilities have changed in the last year, while more than three out of four say their jobs have changed in the last three years. Of those reporting changing jobs in the last year, almost six out of the ten cite technology as the primary reason, followed by reengineering/staff development and downsizing/cost-cutting.

These facts are no surprise to most librarians, but they reinforce the reality of the library world today - things are never going to get back to "normal." Unpredictability and change are the norm.

Being proactive about change rather than being a Pollyanna is essential for future success. Individuals with a Pollyanna mentality believe that change is something that happens to you. In contrast, acquisitions librarians need to be proactive in making change happen. In order to do this, individuals must institute habits that will help them stay ahead of the curve. Managers need to know what is coming. For example, when OCLC was first exploring and developing its PromptCat product, librarians at OSU quickly expressed interest in serving as a test site for this product. As a result, we participated in a beta test that assured us PromptCat would be a valuable and efficient tool for our workflow. Although it was over three years before we could actually begin to use the product because of capabilities of our integrated library system and our vendor, we were still able to plan additional changes during that period with the knowledge that this new tool was coming (Rider and Hamilton 1996).

Scanning the environment and identifying new ideas is one technique to try. For example, individuals can read lessfamiliar newspapers and magazines, talk to new people, or go to unfamiliar places once in a while. These sorts of activities help individuals become more receptive to new ideas. In today's library world, many new ideas are very revolutionary. Professionals must look for and embrace new ideas, as they are the foundation of professional growth and development. But we must not lose sight of the fact that change must be grounded in reason and rationale. We must not change things just because we think it is time to try something new. We must keep in mind the way in which people pick up on new ideas. Shaffer, as quoted by Holt, uses the image of a bell curve as a rule of thumb: Whenever a new idea is presented, we must expect approximately $6 \%$ of the audience to come to the conclusion before us. They are the true visionaries. Another $8 \%$, roughly, are fast to grasp the point and become advocates. About $36 \%$ soon jump on the bandwagon, while another $36 \%$ drag their feet but grudgingly agree to go along. Acceptance then drops off at the same rate, with about $8 \%$ never accepting the idea and $6 \%$ that try to sabotage it (Holt, Stammel, and Field 1996).

\section{BUSinesS SKiLlS}

In the area of business skills, four key areas hold the most importance for the future: financial and contract administration skills, publishing expertise, automation and technical skills, and negotiation skills. The first three have long been part of the acquisitions librarian's skill set and area of expertise. Hewitt $(1989,107)$ reinforces the need for this expertise in a single example:

The bibliographic world and the book trade with which the acquisitions department must deal is international, multilingual, complex and disorganized. Many acquisitions tasks, albeit repetitive, reflect the complexity of interaction with this environment. At the University of North Carolina, for example, a CPA management consultant from the University's Systems and Procedures Department conducted a three-person, month-long study of the Acquisitions Department. He concluded that it was easily the most complex procurement operation he had ever examined. Even more gratifying was his conclusion that the department's procedural complexity was fully justified by the demands of acquiring library materials from 
an international market in a research $\mathrm{l}$ brary environment.

This does not absolve acquisitions librarians of the responsibility to work to eliminate as much of the redundancy and unnecessary complexity as possible, but it does confirm the inherent skills and expertise needed to manage acquisitions effectively.

When talking about financial skills, fiscal management is often a responsibility of both acquisitions and collection development librarians. In libraries where these positions are held by different individuals, each group manages the budget from a different perspective. Generally, collection development librarians have responsibility for allocating the budget and acquisitions librarians take responsibility for insuring that the budget is expended according to the time constraints and regulations required by their institution. The key factor in the area of business skills is the need to keep them up to date as the environment changes, particularly as it relates to the evolution of scholarly communication. Allison and Reid (1994, 31-32) state that:

\section{Ross Atkinson writes that "acquisitions ad- ministrators-who, along with circulation, interlibrary loan, and preservation offi- cers, have primary responsibility for deliv- ery in the paper-based academic library of today-need to begin planning now to ex- pand their knowledge and responsibilities to respond to the new requirements for information delivery in the rapidly ap- proaching age of networked information." He further explains that acquisitions lead- ers, so as to assume a major role, must broaden their knowledge in the economics of publishing and scholarly communica- tion; in electronic publishing; in informa- tion technology and telecommunications.}

If acquisitions librarians have not kept their skills up-to-date in this area, they will be ineffective in dealing with external partners.

For example, the 1988 internal audit of the OSU Acquisition Department focused on items such as the paper order requests submitted by collection managers. Since that time, new auditors, those with electronic data processing (EDP) expertise, have worked with the department on electronic transfer of funds to a serials agent and the entry of order requests directly into the acquisitions system by collection managers. Had the acquisitions librarian not kept her skills up-to-date in the area of audit standards in the EDP area, she would not have been as effective in dealing with these professionals.

In the 1980s, having an extensive understanding of the details of automated acquisitions systems was the most important automation skill needed by acquisitions librarians. In the early stages of system development, this knowledge enabled the acquisitions librarian to redesign internal procedures to maximize use of the system and to work effectively with system designers to improve deficiencies in the system. Today, those details can be left to staff members who work with the system intimately every day. Instead, the acquisitions librarian's focus should be on new technological applications such as learning about the World Wide Web, including the potential uses of web technologies in the department. In addition, the nature of training has changed from formal training delivered in a classroom or off-site to informal collabo ration or individual exploration. Kalin and Clark $(1996,32)$ have captured the essence of this change in their article on technostress:

The rapid change of technology necessitates a different approach to training. ... Staff also have to make a commitment to learn new skills. Training must become an integral part of their work life, not an adjunct activity. An increasing number of li- braries are finding it unrealistic and impractical to provide formal training for every occasion. Rather, they are encouraging and embracing informal, collaborative modes of training.

Negotiation skill is the last business skill in this section, and the area in which acquisitions librarians need the most education. Acquisitions librarians have nego- 
tiated for many things in the past, such as approval contracts and discount schedules. However, today's environment requires librarians to negotiate more often, even down to the individual license agreement, and with more resolve that the library is the customer and can demand and expect to receive more of what it needs and requires. When the term "negotiate" is used, people first think of high-level, large negotiations such as labor contracts. They may also think of more personal negotiations such as buying a car or a house. In reality, people negotiate on a regular basis without even realizing it (Lewicki 1993). Negotiation is simply the discussion that brings about a result or agreement, especially where some element of bargaining is involved. For example, you negotiate when you share scarce resources with a colleague such as printing to a shared printer, or when you divide the chores of daily living with a spouse. These are good examples of negotiation because they aren't governed by rules set by a higher authority.

Once again, space does not permit a detailed discussion of the processes and principles of formal negotiation. Instead, acquisitions librarians should focus on the following thoughts about the results and nature of negotiating:

1. In most situations, there is a solution that will benefit everyone, i.e., the classic win-win. For example, in a license negotiation, in a win-win situation the library gets the product it wants at a reasonable price. The supplier gets to make the sale while preserving the rights that are essential to success.

2. Anything can be negotiated. Not all negotiations result in success, but it is often possible to change or bend the existing rules successfully. When librarians call to discuss a product, they can encounter a set of rigid rules at the customer service level that are not viable for the library's situation. Negotiators do not have to accept responses such as "that's the only way we distribute the product." Instead, they should work their way up the hierarchy until they reach someone who has the authority to discuss and negotiate the terms. Negotiation can be initiated for anything for which the existing terms are not agreeable, although the negotiation might or might not result in a change.

3. Negotiators should always go into a negotiation with more than one option. Each party should be flexible in trying to understand where the difficulty lies for the other party and should look for a solution that meets all concerns (Yeomans 1985).

4. Negotiators must be willing to walk away from the deal. Before getting into a negotiation, acquisitions librarians should work with those in their own organization, such as the collection development officer or director to determine what factors can inhibit the deal. Once agreement is established within the organization about those factors, negotiators will have the knowledge and authority about what compromises can be made and when to walk away from the deal.

\section{Personal Skilles}

Personal skills are a difficult set of attributes to define and articulate because there are so many of them, because they are often intangible, and because there is no consensus on which are the most important. I consider self-leadership (meaning the ability to lead oneself in areas of growth and improvement) as the critical component to the future success of acquisitions librarians. Self-leadership is recognized by most theorists as an essential criterion for successful leaders. It is seen as the foundation on which other personal attributes are built. Five aspects of self-leadership are the focus of this discussion: having a good attitude, making good first impressions, managing stress, assessing one's performance, and using power effectively.

Almost always, individuals control the way in which they respond to things. Nothing in the actual work environment dictates how one reacts to things. It is not 
uncommon for something to happen at work that causes individuals to feel angry. They have two choices about how to respond: they can control or channel anger toward positive results and let it out in appropriate ways, or they can have a positive outlook on what can be achieved. Because individuals have a choice, most of the time they will be better off reacting in a positive rather than a negative way. People like to work with a positive person more than a negative one. Upbeat thinkers are more fun to be around and people have more confidence in them.

It is impossible for people to know what a person thinks and feels deep inside, but they do pick up on what bubbles to the surface. Thus, what a person allows others to see is important. If asked, most people would indicate that they think they are already very positive. However, Yeomans' research has shown that people who listen to tapes of themselves in conversation and meetings are horrified at the amount of negative thinking they do. Librarians must learn to look at each new situation and manage their reactions to it. Changing one's outlook doesn't happen overnight; it is something that an individual has to work on every day. Also, having a positive attitude does not mean that you have to accept everything that comes along without complaint. It does mean you look at each situation and pick the best way to react to it (Yeomans 1985).

Having a good attitude affects the first impressions one makes on others. Obviously, most people are aware of the impact of first impressions in the context of starting a new job or being on a new committee. However, people forget that new "first" impressions are made every dayeven if an individual has worked in the same organization for a long period of time. Individuals have opportunities every day to make good first impressions: when they meet with someone they have not worked closely with before or have not worked with for a long time; when they work with someone who is new to the library; when they work with someone who has taken on new responsibilities; and when they take on new responsibilities themselves. People form opinions very quickly and those opinions might be hard to change later (Yeomans 1985). That is exactly why first impressions are important: they persist longer than later experiences that might serve to refute them.

Controlling reactions and managing first impressions is stressful; the inevitable next problem is how to control and manage the stress that all of this brings to bear. The first rule of stress is that it is normal and can be energizing if used correctly. The second rule of stress is that while it might be good for helping individuals to work better than they do in ordinary situations, it also can be downright disabling. The third rule of stress is that when something goes wrong, it is likely that five or six more things will also go wrong at the same time, driving stress to intolerable levels. The prescription for dealing with these three rules is to attack the outside forces that cause stress, to change the personal habits that contribute to stress, and to improve the ways in which individuals react to stress.

To manage stress, individuals must accept that stress exists. Moreover, they must remember that not all stress is bad when they are planning strategies for dealing with stress. Managers must learn to be-and then remember that they are-good stress managers. To do this, individuals can remind themselves how they have handled similar situations before. It helps to remember that stress usually ends and the duration is not too long. Managers must remember that they are not perfect and should not be too hard on themselves. Admitting that one is stressed to others might be a useful strategy. Another exercise is to ask oneself what could be the worst thing that could happen. During a stressful situation, it is important to decide on a course of action; and after the stressful situation is over, reward oneself (Yeomans 1985).

In a couple of other contexts, I have considered ways to assess the performance of one's department, but let's extend that discussion to talking about ways of assessing the individual's performance. If managers really want to improve, they should not lie to themselves. Managers 
need to recognize their strengths and weaknesses. For example, managers should recognize that strengths include meeting deadlines, using all available resources to get the job done, basing reports on actual results or concrete information, and presenting solutions as well as problems to their supervisors. Common weaknesses include being unprepared for meetings, panicking easily, or leaving projects unfinished. To identify strengths and weaknesses, managers need to ask themselves probing questions about how they behave on the job and whether their actions meet organizational expectations. Typical questions focus on the relationship that managers have with their supervisors, how managers respond to crises, how they prepare reports, and whether they finish assignments and projects on time. Such questions will elicit information that will increase self-awareness. However, self-perception is only half of the equation. Managers must also seek out the perceptions of others about their work and performance. Self-perception and the perceptions of others usually vary and both sets of observations are needed to form a rounded picture.

Finally, the last personal skill is the use of power. Carson, Crason, and Phillips $(1995,26)$ assert that:

\section{Simply stated, power is what managers use to influence others. When employees are cooperative, influence is easily accom- plished. At other times, however, a man- ager might need staff members to do things against their will. It is in these cases that the use of power must be carefully considered.... The challenge facing the library manager is to effectively use power in a manner that minimizes resentment, hostility, and vengeful reactions.}

Of the five types of power, the first three-power to reward, power to punish, and authority-come with the job and, thus, are less useful and more punitive types of power. The higher in an organization you are, the more of these types of power you have. The last two types of power-expertise and referent powerare the most valuable types of power for leaders because they are positive types of power and have the potential to influence the actions of more people than the others. The power associated with expertise occurs when the leader is perceived to possess special knowledge, unique expertise, or rare skills. Referent power results when staff identify with and are attracted to the library manager. This latter type of power ". . . attaches to a leader because people admire him, want to be like him, or are wowed by his integrity, charisma or charm.'... The better the leader ... the more likely he is to rely on the personal sources of power... Really effective leaders almost never have to put the screws to someone" (Sonnenberg 1994). Expertise and charisma undergird vision, ideas, and direction, all of which leaders need to lead. Vision and direction have a greater effect on a larger number of people than a leader expects to reward or punish directly. This is the kind of power to which acquisitions librarians should aspire.

These personal skills are important for acquisitions librarians for a number of reasons. In today's library and the library of the future, the primary role of acquisitions librarians will be managerial. They will continue to collaborate with internal partners, such as librarians in the automation, collection development, and cataloging departments. They will negotiate contracts with vendors, evaluate performance on outsourcing arrangements, and design and coordinate new projects and approaches to operations. The personal skills discussed above are essential components in the successful fulfillment of those responsibilities.

\section{Conclusion}

Today's library environment is a catalyst for significant change. The future of libraries is characterized by a high level of uncertainty where there are not many precedents on which to base decisions. Decisions and courses of action will be made more quickly than ever before and with fewer reliable facts on which to base the decision. In addition, there will be multiple avenues to pursue or several 
plausible options to consider.

Acquisitions librarians who have a vision and are able to set and achieve goals will be valued managers. Managers will be expected to use creativity and innovation to promote information access and delivery such as successful negotiation of licenses for electronic products. There will be greater demand for the rapid delivery of material to users. Acquisitions librarians can play a part in this through adoption of new services and tactics, such as outsourcing, to expedite the delivery and processing of materials. Acquisitions librarians have many skills that will continue to be valuable in the library world of the future. It is imperative that they continue to expand and broaden their skills in management and business as well as develop personal skills to cope with an ever changing environment.

\section{WORKS CITED}

Allison, Terry L, and Marion T. Reid. 1994. The professionalization of acquisitions and collection development. In Recruiting, educating, and training librarians for collection development, ed. Peggy Johnson and Sheila S. Intner, 19-34. Westport, Conn:: Greenwood Press.

Carson, Paula Phillips, Kerry David Carson, and Joyce Schouest Phillips. 1995. The library manager's deskbook: 102 expert solutions to 101 common dilemmas. Chicago: American Library Association.

Hewitt, Joe A. 1989. On the nature of acquisitions. Library resources \& technical services 33: 105-22.

Holt, John W., Jr., Jon Stamell, and Melissa Field, 1996. Celebrate your mistakes and 77 other risk-taking, out-of-the-box ideas from our best companies. Chicago: Irvin Publishing.

Kalin, Sally, and Katie Clark. 1996. Technostressed out? How to cope in the digital age. Library journal 121: 30-32.

Lewicki, Roy J. 1993. Negotiating strategically. In The portable MBA in management, ed. Allan R. Cohen, 147-89. New York: John Wiley.

Lubans, John L. 1994. Sherlock's dog, or man- agers and mess finding Library administration d management 8: 139-49.

Magrill, Rose Mary, and John B. Corbin. 1989. Acquisitions management and collection development in libraries. $2 \mathrm{~d}$ ed. Chicago: American Library Association.

Muir, Holly J. 1995. Benchmarking: What can it do for libraries? Library administration \& management 9: 103-5.

Nisonger, Thomas E. 1994. Should courses in acquisitions and collection development be combined or separate? In Recruiting, educating, and training librarians for collection development, ed Peggy Johnson and Sheila S. Intner, 127-43. Westport, Conn.: Greenwood Press.

Olaisen, Johan, Hugo Lovhoiden, and Olav A. Djupvik, 1995. The innovative library: Innovation theory applied to library services. Libri 45: 79-90.

Phillips, Nicola, 1993. Innovative management: A pragmatic guide to new techniques. London: Pitman Publishing.

Reid, Marion T. 1995. Closing the loop: How did we get here and where are we going? Library resources of technical services 39 : 267-73.

Rider, Mary M, and Marsha Hamilton. 1996. PromptCat issues for acquisitions: Quality review, cost analysis and workflow implications. Library acquisitions: practice o theory 20: 9-22.

St. Lifer, Evan. 1996, Net work: New roles, same mission. Library journal 121: 26-30.

Sonnenberg, Frank K. 1994. Managing with a conscience: How to improve performance through integrity, trust, and commitment. New York: McGraw Hill.

Thompson, LeRoy, Jr, 1994. Mastering the challenges of change: Strategies for each stage in your organization's life cycle. New York: AMACOM.

Vaill, Peter B. 199.3, Visionary leadership. In The portable MBA in management, ed. Allan R. Cohen, 12-37. New York: John Wiley.

Van Fleet, James K. 1973. The 22 biggest mistakes managers make and hou to correct them. West Nyack, N.Y. Parker Publishing.

Yeomans, William N. 1985. 1000 things you never learned in business school: How to get ahead of the pack \& stan there. New York: McGraw-Hill. 